\title{
Transparent tetragonal-cubic zirconia composite ceramics densified by spark plasma sintering and hot isostatic pressing
}

\author{
Apurv Dash* ${ }^{a}$, Byung-Nam KIM ${ }^{b}$, Jens Klimke ${ }^{c}$, Jef Vleugels ${ }^{a}$ \\ ${ }^{a}$ KU Leuven, Department of Materials Engineering, B-3001 Heverlee, Belgium \\ ${ }^{\mathrm{b}}$ National Institute for Materials Science, 1-2-1 Sengen, Tsukuba, Ibaraki 305-0047, Japan \\ ${ }^{c}$ Polycrystal design GmbH, Dresden, Germany
}

\begin{abstract}
Targeting higher toughness transparent ceramics, tetragonal ( $3 \mathrm{~mol} \%$ yttria) and cubic ( $8 \mathrm{~mol} \%$ yttria) $\mathrm{ZrO}_{2}$ starting powder mixtures were densified by spark plasma sintering (SPS) in vacuum at $1100^{\circ} \mathrm{C}$ and post hot isostatic pressing (HIP) in argon at $1100^{\circ} \mathrm{C}$. The influence of the ultra-fine microstructure and phase composition on the fracture resistance and light transmission in the visible and infra-red range was assessed. Of special interest was the influence of a thermal annealing step in air on the transparency of the SPS and SPS-HIP ceramics.
\end{abstract}

\section{Introduction}

The prerequisite for transparency in ceramics is a very high sintered density, because residual pores can cause substantial light scattering, rendering the ceramic opaque [1]. Since zirconia has a very high refractive index ( 2.2 ), there have been efforts to sinter zirconia ceramics to combine optimal optical, mechanical and thermal properties [2-5]. Such materials can be used as optical lenses [6] and laser windows [7]. The tetragonal phase of zirconia has the potential of transformation toughening, which makes it very attractive for transparent ceramics. Since residual pores are detrimental to the transparency of $\mathrm{ZrO}_{2}$ ceramics, an extemal pressure is often used during sintering [8]. Although there are certain ceramics like yttrium aluminium gamet (YAG) which can be pressureless sintered to transparency, this is not the case for zirconia ceramics. Zhang et al. sintered transparent $8 \mathrm{~mol} \% \mathrm{Y}_{2} \mathrm{O}_{3}$ fully stabilized cubic zirconia (8YSZ) by spark plasma sintering (SPS) with an uniaxial pressure of $400 \mathrm{MPa}$ at $1100^{\circ} \mathrm{C}[9,10]$. The same group also attempted the sintering of tetragonal zirconia under similar conditions, but the sintered ceramic was not transparent in the visible light region but rather transparent in the infra-red region [11]. Klimke et al. were able to achieve a real in-line transmission of $14 \%$ at a wavelength of $640 \mathrm{~nm}$ for tetragonal zirconia ceramics by densifying an in-house synthesized nanometric tetragonal zirconia powder. Sintering to closed porosity was done in air, followed by a HIP treatment at $1100^{\circ} \mathrm{C}$ and $200 \mathrm{MPa}$ of argon [12]. Anselmi et al. showed that a pressure of around 800 $\mathrm{MPa}$ and a temperature of $950^{\circ} \mathrm{C}$ were required to sinter a $3 \mathrm{~mol} \% \mathrm{Y}_{2} \mathrm{O}_{3}$ stabilised $\mathrm{ZrO}_{2}$ (3YSZ) to transparency, starting from commercial nanometric powders [13]. Tsukuma et al. started with commercial cubic zirconia powders and sinter-HIPed the ceramics at $1350-1750^{\circ} \mathrm{C}$. When HIPed at 
$1350^{\circ} \mathrm{C}$, pre-sintering was beneficial for obtaining transparent zirconia with a transparency comparable to that of a single crystal after HIPing [14]. In the present work, a combination of SPS and HIP is used for densification of zirconia ceramics. SPS has the advantage of a short processing time and ability to achieve a very high density and HIP eliminates the residual porosity by the applied external hydrostatic pressure.

Transparent 3YSZ ceramics have the potential to combine optical transparency with a high fracture toughness and strength. However, 3YSZ has a mainly tetragonal crystal structure and has a different refractive index along different crystallographic directions, which results in birefringent light scattering at the grain boundaries. The light scattering at the grain boundaries between anisotropic grains makes it less transparent than the cubic polymorph. The birefringent scattering can be reduced by having a grain size far below the wavelength of visible light so that there is no strong interaction of the light waves with the grain boundaries where a discontinuity in the refractive index exists. Decreasing the grain size has a profound effect on the transparency of alumina ceramics, but tetragonal phase zirconia has a one order higher birefringence than alumina, hence the grain size requirements for tetragonal zirconia are very stringent [12]. For a fixed composition of $3 \mathrm{Y}-\mathrm{ZrO}_{2}$ decreasing the grain size reduces the phase transformability thereby compromising the toughness. Below a critical grain size, the tetragonal zirconia phase is size stabilized and no longer transformable [15]. Hence decreasing the grain size of tetragonal zirconia ceramic will not result in transparent and tough zirconia ceramics, implying it is both a scientific and technological challenge to fabricate transparent and tough zirconia ceramics. In the present work, we have addressed this challenge and have fabricated transparent zirconia ceramics with a moderate toughness. Our approach aimed for a cubic zirconia matrix ceramic with a well-dispersed tetragonal zirconia phase to combine the toughness of tetragonal zirconia and the transparency of cubiczirconia.

\section{Experimental Procedure}

Commercially available 3 mol\% $\mathrm{Y}_{2} \mathrm{O}_{3}$-stabilised $\mathrm{ZrO}_{2}$ and 8 mol\% $\mathrm{Y}_{2} \mathrm{O}_{3}$-stabilised $\mathrm{ZrO}_{2}$ (grade TZ-3Y \& TZ$8 Y$ respectively, Tosoh Corporation, Tokyo, Japan) were used as starting powders. Compositions with varying amounts of TZ-3Y and $\mathrm{TZ}-8 \mathrm{Y}$ were prepared by mixing calculated weights of powders in ethanol in a polyethylene bottle in the form of a slurry. The mixing was carried out with $\mathrm{ZrO}_{2}$ milling media ( $\Phi$ $5 \mathrm{~mm}$, grade TZ-3Y, Tosoh) on a multidirectional mixer (Turbula, WAB, Switzerland) for $24 \mathrm{hrs}$. Table 1 shows the composition of the materials with their respective sample IDs. The slurry was dried in a round bottom flask with a vertical column evaporator at $60^{\circ} \mathrm{C}$ for $8 \mathrm{hrs}$., followed by sieving on a $100 \mu \mathrm{m}$ sieve to have a uniform agglomerate size. The sieved powder was loaded in a graphite die $(\Phi 30 \mathrm{~mm})$ with a carbon fiber reinforced sleeve to sustain radial stresses. The die was wrapped with graphite felt to reduce radiation heat losses. $0.35 \mathrm{~mm}$ thick graphite paper was used to avoid contact of the ceramic powder with the walls of the die and punch. High strength TZM alloy punches were used.

Sintering was carried out in a spark plasma sintering furnace (Type HP D25/1, FCT Systeme, Frankenblick, Germany) with a pulse time of $10 \mathrm{~ms}$ followed by a pause time of $5 \mathrm{~ms}$. The sintering was carried out at $1100^{\circ} \mathrm{C}$ under a uniaxial pressure of $200 \mathrm{MPa}$. The temperature was raised to $800^{\circ} \mathrm{C}$ at $50^{\circ} \mathrm{C} / \mathrm{min}$ and a minimum pressure of $4 \mathrm{MPa}$ to maintain contact of the punches, protection plates and the electrode. The pressure was raised rapidly to $200 \mathrm{MPa}$ within 1 minute upon reaching $800^{\circ} \mathrm{C}$. The heating rate was maintained at $10^{\circ} \mathrm{C} / \mathrm{min}$ at constant ramp to the peak temperature of $1100^{\circ} \mathrm{C}$ with a 
holding time of 20 minutes, after which the pressure was rapidly released to $4 \mathrm{MPa}$ within 30 seconds. Cooling was controlled at a rate of $50^{\circ} \mathrm{C} / \mathrm{min}$ to $500^{\circ} \mathrm{C}$ followed by natural cooling. A first set of SPS samples was exposed in air at $800^{\circ} \mathrm{C}$ for $25 \mathrm{hrs}$. in a muffle furnace (Carbolite, UK) to get rid of the carbon contamination from the graphite paper prior to hot isostatic pressing. These samples were densified in a graphite-free hot isostatic press (Bodycote HIP Ltd., Chesterfield, UK) at a temperature of $1100^{\circ} \mathrm{C}$ with a heating rate of $10^{\circ} \mathrm{C} / \mathrm{min}$ in $200 \mathrm{MPa}$ of argon. The soaking time at $1100^{\circ} \mathrm{C}$ was 15 hours. The sintered samples were sand blasted, plane parallel ground on both sides and mirror polished on both sides with diamond slurry. The SPS-HIP ceramics along with a second set of only SPS ceramics were annealed in air at $700^{\circ} \mathrm{C}$ for $100 \mathrm{hrs}$. to regain the oxygen stoichiometry.[10]

The density of the ceramics was determined by the Archimedes' method in water. The polished and annealed samples were scanned in a $\theta-2 \theta$ X-ray diffractometer (XRD, Seifert, Ahrensburg, Germany) using $\mathrm{Cu}-\mathrm{K}_{\alpha}$ radiation $(40 \mathrm{kV}, 40 \mathrm{~mA})$. The scan was performed with a step size of $0.02^{\circ}$ and a step time of 1 second. Analysis of the XRD pattern was done with X'Pert Highscore Plus software. All ceramics were thermally etched at $1000^{\circ} \mathrm{C}$ in air for 1 hour for microstructural investigation. The microstructure of the polished surfaces was examined by scanning electron microscopy (Nova NanoSEM 450, FEI). The indentation fracture toughness $\mathrm{K}_{/ C}$ was calculated by the Anstis formula, with a Young's modulus of 200 GPa, based on the measured crack pattern originating at the edges of the Vickers indentation (Model FV-700, Future-Tech Corp., Tokyo, Japan). The hardness $\left(\mathrm{HV}_{10}\right)$ and fracture toughness $\left(\mathrm{K}_{l c}\right)$ were measured with an indentation load of $98.1 \mathrm{~N}$ and the average of 5 indentations was calculated. The total forward transmission (TFT) was measured in the wavelength range of 240-1600 nm using a double beam spectrophotometer (SolidSpec-3700DUV, Shimadzu Co. Ltd., Kyoto, Japan) equipped with an integration sphere. To simplify comparison, the measured TFT on an arbitrary thickness was converted to the corresponding TFT for $1 \mathrm{~mm}$ thick samples using the following relation [16]:

$$
T_{2}=\left(1-R_{S}\right)\left(\frac{T_{1}}{\left(1-R_{S}\right)}\right)^{t_{2} / t_{1}}
$$

With $R_{s}$, the specular reflection loss on both surfaces of zirconia $(=0.25)$ and $T_{1}$ and $T_{2}$ correspond to the transmission at a thickness $t_{1}$ and $t_{2}$. The same samples were measured before and after annealing/SPS and annealing/SPS-HIP treatment.

Electron backscattered diffraction (EBSD, EDAX, Netherlands) imaging was done on selected annealed ceramics to assess the distribution of the zirconia phases, based on the Kikuchi patterns of the respective phases. The voltage used for EBSD pattern acquisition was $5 \mathrm{kV}$. The lattice parameters of the respective phases were calculated by Rietveld analysis (Topas) and the cif file for Kikuchi pattem acquisition was created. The step size for EBSD was set to $10 \mathrm{~nm}$, which was the lower limit of the stage control of the microscope. The grain orientation maps were generated using EDAX OIM analysis software.

\section{Results and discussions}

The density of the SPS-HIP zirconia ceramics linearly increases with increasing tetragonal phase content, as shown in Fig. 1. This is a probable evidence for the fact that there is no significant redistribution of yttria during the HIP process at $1100^{\circ} \mathrm{C}$ and the original ratio of cubic to tetragonal phase was 
maintained. Moreover, the residual porosities (SEM) suggest that cubic zirconia has a poor sinterability inducing a decrease in density. The applied sintering temperature is well below the onset temperature $\left(>1200^{\circ} \mathrm{C}\right)$ for cubic phase formation in a 3Y-TZP ceramic [17], implying that the 0C100T ceramic is fully tetragonal. Fig. 2 shows the XRD patterns of the SPS-HIP ceramics, a magnified embedded graph shows the distinct peaks of the tetragonal and cubic phases in the $81-86^{\circ} 2 \theta$ range. The doublet peak around $82^{\circ}$ and $84^{\circ} 2 \theta$ is characteristic for the tetragonal zirconia phase, whereas the cubic zirconia phase only has a single peak. No monoclinic $\mathrm{ZrO}_{2}$ was observed.

Scanning electron micrographs of thermally etched $\left(1000^{\circ} \mathrm{C}\right.$ for 1 hour in air) SPS ceramics before and after HIP ( $15 \mathrm{hrs}$. at $1100^{\circ} \mathrm{C}$ ) are compared in Fig. 3. The microstructures of the OC100T (Fig. 3.a, d) and 50C50T (Fig. 3.b, e) are fully dense. The SPS 100C0T ceramic (Fig. 3.c) shows a few small grain boundary pores, whereas the HIP 100C0T (Fig. 3.f) has a substantially larger grain size with a higher porosity. These pores might have formed during the HIP process, where grain growth resulted in the coalescence of oxygen vacancies. Thermal etching of the ceramics for microscopy at $1000^{\circ} \mathrm{C}$ for 1 hour in air might have resulted in the annihilation of coalesced oxygen vacancies into pores. Although the HIP treatment was performed at only $1100^{\circ} \mathrm{C}$, Ostwald ripening was clearly active in the 100COT ceramic [18]. The average grain size in the microstructures decreased with increasing fraction of tetragonal zirconia phase, because of the segregation of $\mathrm{Y}^{3+}$ to the grain boundaries in 3Y-TZP ceramics, which resulted in a solute drag effect [19]. In cubic zirconia, the uniform distribution of yttria has been reported not have a solute drag effect [20], which could explain the pronounced grain growth in the SPS and HIP 100COT.

The grain size distribution of the individual constituent $\mathrm{ZrO}_{2}$ phases in the 0C100T and 50C50T ceramics could not be quantified from the microstructure because it is not possible to differentiate the tetragonal and cubic zirconia grains by secondary or back-scattered electron imaging contrast in the scanning electron microscope. Ceramics with an intermediate content of tetragonal zirconia (50C50T) have inhibited grain growth because of the discontinuity of both cubic and tetragonal phases. There are some larger grains observed in the 50C50T ceramics, which are most probably cubic phase grains. The cubic grains are larger than the tetragonal grains, so the grain size distribution is bimodal. The mobility of the tetragonal-tetragonal grain boundary is obviously lower than for the cubic-cubic grain boundary because of $\mathrm{Y}^{3+}$ segregation. The cubic-tetragonal grain boundaries might have an asymmetric distribution of $\mathrm{Y}^{3+}$ across the grain boundary [20], resulting in a higher grain boundary mobility than for tetragonaltetragonal boundaries, but lower than for cubic-cubic grain boundaries [19,21,22].

The discrimination of tetragonal and cubic zirconia phases is difficult because of similar crystal lattice parameters and chemical composition. Moreover, it is very difficult to map each phase based on the yttria content by means of EDS or WDS analysis because of the too large interaction volume of the electron beam which is larger than the grain size of the sintered ceramics in this work [23]. Since tetragonal and cubic zirconia phases have different Kikuchi patterns, it should however be possible to distinguish these two chemically and structurally very similar phases. An EBSD scan was performed on the SPS-HIP 50C50T ceramic. Fig. 4 shows the distinct cubic and tetragonal grain EBSD maps. The 50C50T ceramic was selected since it contains equal amounts of tetragonal and cubic phases and would be representative for the microstructure and phase distribution of ceramics with other compositions. It is evident from the phase map that the tetragonal grains are very small, whereas the cubic grains are substantially larger. The area fraction of cubic and tetragonal grains, as measured from the phase maps, in the HIP 50C50T was 0.54 and 0.46 respectively, and 0.51 and 0.49 for the SPS 50C50T. 
The grain size distribution of the cubic and tetragonal grains for both SPS and SPS-HIP 50C50T ceramics is presented in Fig. 5. Since the cubic and tetragonal grains looked similar in the SEM micrograph, it was not possible to calculate the individual grain sizes by conventional methods. The EBSD software (EDAX OIM) could directly give the grain size distribution of cubic and tetragonal grains separately. The average grain size of cubic and tetragonal phase in the SPS-HIP ceramic are $103 \mathrm{~nm}$ and $27 \mathrm{~nm}$ respectively, and $87 \mathrm{~nm}$ and $28 \mathrm{~nm}$ respectively in the SPS ceramic. The tetragonal grains retained their average small initial grain size, but the peak maximum clearly shifted to a smaller grain size, indicating that the smaller $\mathrm{c}-\mathrm{ZrO}_{2}$ grains have grown at the expense of large $\mathrm{t}-\mathrm{ZrO}_{2}$ grains. The grain size of the cubic phase was not influenced during HIP.

Wood et al. measured the refractive index of cubic $12 \mathrm{Y}-\mathrm{ZrO}_{2}$ as a function of the wavelength [2]. The refractive index varies from 2.25 at $400 \mathrm{~nm}$ to 2.10 at $1800 \mathrm{~nm}$ wavelength range. Accordingly, the theoretical maximum transmission is $71 \%$ at $400 \mathrm{~nm}$ and $74 \%$ at $1800 \mathrm{~nm}$. To simplify the estimation of the theoretical maximum of cubic zirconia ceramics with birefringent tetragonal zirconia grains, a mean refractive index of 2.19 was considered which corresponds to a theoretical maximum of $75.5 \%$, as indicated by the dashed line in Fig. 6, 7 and 8, assuming there is no scattering by grain boundaries or pores and only the specular reflection on both surfaces are taken into consideration for the loss in transmission. The theoretical maximum transmission was calculated by the following formula [24]:

$$
T_{\text {Total forward transmission }}=1-R_{S}
$$

Where $R_{s}$ is the specular reflection at the top and bottom of the surface and is given by:

$$
R_{s}=1-\frac{2 n}{n^{2}+1}
$$

And $\mathrm{n}$ is the mean refractive index for the zirconia ceramics.

The total forward transmission of the as-SPS ceramics are presented in Fig. 6.(a). The ceramic grades follow the expected trend of a decreasing transmission with increasing tetragonal zirconia phase content because of the birefringent scattering nature of the tetragonal phase. According to the RayleighGans-Debye theory, the scattering is more pronounced at lower wavelengths and hence the transmission for all ceramics is higher at higher wavelengths [25]. The fact that the transmission of the 0C100T is higher than for 10C90T, 30C70T and 50C50T but lower than for 70C30T in the 1200-1600 nm range indicates that the amount of cubic/tetragonal grain boundaries should be minimized or completely eliminated. The overall TFT of the SPS ceramics is low, due to the generation of color centers, i.e. oxygen vacancies with one $\left(\mathrm{F}^{+}\right.$centers) or two ( $\mathrm{F}$ centers) trapped electrons, during SPS treatment in vacuum and at high carbon activity [26]. These color centers cause a strong light absorption and reduce the light transmission. The color centers can however be annihilated by long term annealing in air, restoring the in-line transmission.

The transmission data of SPS annealed ceramics are represented in Fig. 6 (b). It is noteworthy that the transmission of OC100T below $450 \mathrm{~nm}$ is the highest which might be due to the smallest grain size and concomitant lowest light scattering. The 0C100T is also the only ceramic with an apparent transmission plateau in the wavelength range of $500-800 \mathrm{~nm}$ which is actually caused by an enhanced light transmission in the visible light region $(400-700 \mathrm{~nm})$. This can only be attributed to a more efficient annihilation of the color centers compared to the other ceramics, within the time frame of the 100 hours annealing in air at $700^{\circ} \mathrm{C}$. The $30 \mathrm{C} 70 \mathrm{~T}$ has a TFT that is comparable to the OC100T below $500 \mathrm{~nm}$ 
and has a similar TFT as 90C10T at higher wavelengths. Despite having a higher tetragonal phase content, the transmission of 30C70T is comparable to 90C10T. 30C70T is a composition with the highest tetragonal phase content in combination with a continuous percolation of cubic phase grains. Since the cubic phase grains do not scatter light due to birefringence, a possible continuous percolation of the same may result in a higher transmission level.

The TFT of the SPS-HIP ceramics before and after air-annealing at $700^{\circ} \mathrm{C}$ for 100 hours, presented in Fig. 7 , is overall higher to their SPS equivalents (Fig. 6(a)) because of the elimination of residual porosity and concomitant reduced scattering. Since the SPS OC100T already had a very high density after SPS, the HIP treatment only led to the formation of additional color centers, increasing light absorption and deteriorating the transparency. The difference in transmission of the SPS-HIP ceramics with different tetragonal zirconia content (Fig. 7a) can be attributed to the different reduction potential of $3 \mathrm{Y}-\mathrm{ZrO}_{2}$ and $8 \mathrm{Y}-\mathrm{ZrO}_{2}$ due to their different initial oxygen vacancy concentration. The air-annealed SPS-HIP ceramics (Fig. 7.b), except the 70C30T, have a comparable TFT in the visible wavelength range. Air annealing resulted in the removal of color centers responsible for light absorption, with the formation of a profile similar to the one observed for the air annealed SPS 0C100T.

The transmission trend is similar for both SPS and SPS-HIP ceramics (Fig. 6.a and 7.a). Although 100C0T has the highest content of cubic zirconia phase, it does not have the highest transmission in the visible wavelength range because of residual porosity (see Fig. 3 c and f). In Fig. 7.b, 90C10T has the highest transmission in the visible light region, followed by 30C70T which has the highest TFT at higher wavelengths. The trend in transmission is similar to that of air annealed SPS ceramics but the longer dwell time during HIP resulted in a higher cubic phase in 30C70T.

The zirconia ceramics were reduced both during SPS and SPS-HIP operation. The presence of the graphite environment and vacuum during SPS resulted in a more reduced ceramic with a black appearance, compared to the Ar atmosphere during HIP, despite the substantially shorter dwell time. The graphite environment during SPS may have resulted in the formation of a $\mathrm{CO} / \mathrm{CO}_{2}$ atmosphere in the powder compact during densification. The reduction level of the zirconia ceramics can be assessed by comparing the TFT of $100 \mathrm{COT}$ at $400 \mathrm{~nm}$ (see Fig. 8.a). The results of the transmission analysis of the SPS and SPS+HIP 100COT and OC100T ceramics before and after air annealing are presented in Fig. 8 . As the TFT of SPS annealed and SPS-HIP annealed 100COT at $400 \mathrm{~nm}$ are the same, it can be assumed that the transmission level difference of SPS and SPS-HIP 100C0T is only due to a difference in amount of color centers and not due to residual porosity, which is clearly higher for SPS. The TFT is almost zero after SPS and around 5\% after SPS-HIP. The reduction effect of the SPS and HIP operation can be compared independently because the ceramics were annealed in air for $25 \mathrm{hrs}$ at $800^{\circ} \mathrm{C}$ after SPS operation prior to the HIP treatment.

The transmission levels measured before annealing are substantially lower, because of absorption by color centers. The photograph of SPS-HIP 90C10T (Fig. 7.a) shows a yellowish shade, whereas after annealing in air (Fig. 7.b) the ceramic looks white with a higher transparency. The transmission levels before annealing (both SPS and SPS-HIP) of 100C0T are higher than for 0C100T, implying that the heat treatment under low oxygen partial pressure had a much more pronounced effect on the light absorption of the tetragonal $\mathrm{ZrO}_{2}$ ceramic. 
Fig.8. a shows that the transmission of the SPS-HIP cubic zirconia is higher than the SPS zirconia because of elimination of residual porosity, and a lower degree of reduction. The annealed SPS-HIP cubic zirconia has a higher transmission compared to the annealed SPS zirconia in the visible wavelength range, but it is lower than the SPS-annealed ceramic in the infra-red wavelength range. Although most, if not all, of the color centers could be annihilated during air annealing, we think that a substantial amount of the oxygen vacancies might have coalesced into immobile nanopores during the long HIP processing time in argon, whereas this was limited during the short SPS time. Similar as reported for the influence of the SPS temperature on the optical properties of translucent zirconia [26], this nanoporosity cannot be annihilated and results in a reduced TFT of the annealed SPS-HIP 100COT due to enhanced scattering. Although thermal etching of the SPS-HIP 100COT ceramic was only performed for $1 \mathrm{hr}$ in air at $1000^{\circ} \mathrm{C}$, indirect evidence of the formation of this nanoporosity is provided in Fig. 3.f.

The transmission of the SPS and SPS-HIP OC100T ceramic (Fig. 8.b) is comparable in the visible light region because the density of the SPS ceramic was already very high after SPS due to the fine starting particle size. The HIP treatment resulted in additional oxygen vacancies and accompanying color centers, as can be deduced from the lower transmission in the $700-1600 \mathrm{~nm}$ range. HIP caused more color centers than SPS in the 0C100T, whereas it is the opposite for $100 \mathrm{COT}$. 100C0T has a higher point defect concentration than $0 \mathrm{C} 100 \mathrm{~T}$ and hence a higher ionic conductivity at $1100^{\circ} \mathrm{C}$ (sintering temperature). SPS operation combines high temperature, low oxygen partial pressure and electric current. This facilitates the formation of oxygen vacancies in 100C0T because of the ionic conduction through the ceramic. The high amount of current flowing through the sample acts as a driving force for the creation of oxygen vacancies [27]. On the other hand, HIP is a combination of high temperature and an oxygen deficient atmosphere. The formation of oxygen vacancies during HIP needs the diffusion of ions through the bulk and across the grain boundary. A possible increase in density by elimination of residual porosity is not reflected in the transmission data because the absorption of light by oxygen vacancies shadows the effect of a density difference. The increased density of OC100T after HIP however is clearly reflected by the fact that the transmission of the SPS-HIP annealed OC100T is higher than for the SPS annealed ceramic, assuming all color centers were annihilated.

The evolution of the indentation fracture toughness of air SPS-HIP annealed and SPS annealed zirconia ceramics as a function of the tetragonal phase content, along with the TFT at $640 \mathrm{~nm}$ before and after air annealing is presented in Fig. 9. The increase in fracture toughness of annealed ceramics and decrease in TFT of un-annealed ceramics with increasing tetragonal phase content is obvious. Moreover, the $640 \mathrm{~nm}$ TFT levels of air annealed zirconia ceramics are substantially higher than for the nonannealed ceramics.

The fracture toughness of SPS and SPS-HIP OC100T is around 3.3 and $2.6 \mathrm{MPa} \cdot \mathrm{m}^{1 / 2}$ respectively, which is comparable to that of a non-transforming 3Y-TZP reported to be around $\sim 3.8 \mathrm{MPa} \mathrm{m} \mathrm{m}^{1 / 2}$ for nontransformable 3Y-TZP with a grain size of 200-250 nm [28] and $3.3 \mathrm{MPa} \cdot \mathrm{m}^{1 / 2}$ in general [29], butlower than for conventional transformation toughened tetragonal zirconia ceramics [4].

The XRD pattems of polished and fractured surfaces of SPS-HIP OC100T in the $2 \theta$ region of $27-38^{\circ}$ and $72-76^{\circ}$ are compared in Fig. 10. The intensity reversal of the tetragonal doublets in the $34-36^{\circ}$ and $72-$ $76^{\circ} 2 \theta$ range, corresponding to the $(002 / 200)$ and $(004 / 400) t-\mathrm{ZrO}_{2}$ planes respectively (of $\mathrm{I}_{002} / \mathrm{I}_{200}$ and $\mathrm{I}_{004} / \mathrm{I}_{400}$ intensity ratio of 0.26 and 0.19 respectively on the polished surface and 1.05 and 0.88 respectively on the fractured surface) has been attributed to a reorientation of the tetragonal phase by 
ferro-elastic domain switching [30], which has also been observed on ground [31,32] and $\mathrm{Al}_{2} \mathrm{O}_{3}$ blasted [32] $\mathrm{ZrO}_{2}$ surfaces. The toughness contribution by ferro-elastic domain switching for 3Y-TZP was reported to be around 3-4 MPa.m ${ }^{1 / 2}$ for large grained $t^{\prime}$ zirconia ceramics [33]. In the present work however, no evidence for the presence of the $\mathrm{t}^{\prime}-\mathrm{ZrO}_{2}$ phase, defined as a $\mathrm{t}-\mathrm{ZrO}_{2}$ phase with a tetragonality (c/ $\sqrt{2} \mathrm{a}$ ) between 1.005-1.007 and (004)' and (400)' doublet peaks in-between those of the normal $\mathrm{t}-\mathrm{ZrO}_{2}$ doublet in the $72-76^{\circ} 2 \theta$ region, was found, as presented in Fig. $10 \mathrm{c}$ and $\mathrm{d}$. The potential contribution of ferro-elastic domain switching in the present $\mathrm{t}-\mathrm{ZrO}_{2}$ phase containing ceramics should however be limited due to the ultra-fine grains which will constrain the domain reorientation.

Monoclinic zirconia peaks were not observed in the XRD pattems of fracture surfaces, as shown in Fig. $10 \mathrm{a}$. There is also no $\mathrm{t}$ to $\mathrm{m}$ transformation toughening as suggested by the absence of any monoclinic zirconia peaks in Fig. $10 \mathrm{~b}$. The lack of martensitic phase transformability at room temperature is most probably due to the very small grain size which in turn reduces the overall transformability and concomitant toughness. It is however noteworthy that the toughness of the OC100T ceramics is still substantially higher than that of a $8 \mathrm{Y}$ cubic $\mathrm{ZrO}_{2}$ ceramic, i.e. $1.5 \mathrm{MPa} \mathrm{m}^{1 / 2}$ [34].

The toughening contribution by the presence of the $\mathrm{t}-\mathrm{ZrO}_{2}$ phase in the investigated SPS and SPS-HIP ceramics is attributed to the higher intrinsic fracture toughness of non-transformable tetragonal $\mathrm{ZrO}_{2}$ compared to cubic $\mathrm{ZrO}_{2}$, which explains the linear increase in toughness with increased $\mathrm{t}-\mathrm{ZrO}_{2}$ phase content. Moreover, the SPS ceramic grades have a higher toughness than the corresponding SPS-HIP ceramic grades. This might be due to a higher fraction of cubic phase in SPS-HIP grades, which might have formed during HIP by grain growth of cubic grains at the expense of smaller tetragonal grains.

\section{Conclusions}

Tetragonal, cubic and mixed-phase transparent zirconia ceramics were produced by spark plasma sintering in combination with hot isostatic pressing. The total forward transmission (TFT) at $640 \mathrm{~nm}$ of the as-SPS and as-SPS-HIP ceramics decreased almost linearly from 10-15\% for c-ZrO ${ }_{2}$ down to 0 for $\mathrm{t}$ $\mathrm{ZrO}_{2}$. However, annealing the SPS and SPS-HIP ceramics in air at $700^{\circ} \mathrm{C}$ for $100 \mathrm{hrs}$ enhanced the TFT by annihilation of the oxygen vacancies generated during SPS and HIP. After air annealing, the TFT of the SPS ceramics fluctuated between 15 and $40 \%$, whereas the TFT of the annealed SPS-HIP ceramics was $\sim 40 \%$ irrespective of the $\mathrm{t}-\mathrm{ZrO}_{2}$ content, highlighting the importance of the pore elimination during HIP. The indentation fracture toughness varied linearly between $1.25 \mathrm{MPa} \cdot \mathrm{m}^{1 / 2}$ for the $\mathrm{c}-\mathrm{ZrO}_{2}$ up to 3.0 $\mathrm{MPa} . \mathrm{m}^{1 / 2}$ for the $\mathrm{t}-\mathrm{ZrO}_{2}$. Air annealing of SPS-HIP $\mathrm{ZrO}_{2}$ allowed to obtain a transparent $\mathrm{t}-\mathrm{ZrO}_{2}$ ceramic with the same TFT ( $40 \%$ at $640 \mathrm{~nm}$ ) as a c- $-\mathrm{ZrO}_{2}$, but with a substantially higher fracture toughness. No

martensitic phase transformation contribution was observed and the SPS-HIP tetragonal zirconia showed evidence of ferro-elastic domain switching upon fracturing.

\section{Acknowledgements}

The authors would like to thank Dr. Gokula K. Muralidharan and Dr. Nachiketa Ray for the SEM and EBSD investigations.

\section{References}

[1] A. Krell, J. Klimke, T. Hutzler, Transparent compact ceramics: Inherent physical issues, Opt. Mater. (Amst). 31 (2009) 1144-1150. doi:10.1016/j.optmat.2008.12.009.

[2] D.L. Wood, K. Nassau, Refractive index of cubiczirconia stabilized with yttria, Appl. Opt. 21 (1982) 
2978. doi:10.1364/AO.21.002978.

[3] S. Ghosh, D. Teweldebrhan, J.R. Morales, J.E. Garay, A.A. Balandin, Thermal properties of the optically transparent pore-free nanostructured yttria-stabilized zirconia, J. Appl. Phys. 106 (2009) 113507. doi:10.1063/1.3264613.

[4] R.C. Garvie, R.H. Hannink, R.T. Pascoe, Ceramic steel?, Nature. 258(1975) 703-704. doi:10.1038/258703a0.

[5] S. Heiroth, R. Ghisleni, T. Lippert, J. Michler, A. Wokaun, Optical and mechanical properties of amorphous and crystalline yttria-stabilized zirconia thin films prepared by pulsed laser deposition, Acta Mater. 59 (2011) 2330-2340. doi:10.1016/J.ACTAMAT.2010.12.029.

[6] U. Peuchert, Y. Okano, Y. Menke, S. Reichel, A. Ikesue, Transparent cubic-ZrO2 ceramics for application as optical lenses, J. Eur. Ceram. Soc. 29 (2009) 283-291.

doi:10.1016/j.jeurceramsoc.2008.03.028.

[7] Y. Damestani, C.L. Reynolds, J. Szu, M.S. Hsu, Y. Kodera, D.K. Binder, B.H. Park, J.E. Garay, M.P. Rao, G. Aguilar, Transparent nanocrystalline yttria-stabilized-zirconia calvarium prosthesis, Nanomedicine Nanotechnology, Biol. Med. 9(2013) 1135-1138. doi:10.1016/j.nano.2013.08.002.

[8] I. Yamashita, K. Tsukuma, Light scattering by residual pores in transparent zirconia ceramics, J. Ceram. Soc. Japan. 119 (2011) 133-135. doi:10.2109/jcersj2.119.133.

[9] H.B. Zhang, B.-N. Kim, K. Morita, H. Yoshida, J.-H. Lim, K. Hiraga, Optimization of high-pressure sintering of transparent zirconia with nano-sized grains, J. Alloys Compd. 508 (2010) 196-199. doi:10.1016/j.jallcom.2010.08.045.

[10] H. Zhang, B.N. Kim, K. Morita, H. Yoshida, J.H. Lim, K. Hiraga, Optical properties and microstructure of nanocrystalline cubic zirconia prepared by high-pressure spark plasma sintering, J. Am. Ceram. Soc. 94 (2011) 2981-2986. doi:10.1111/j.1551-2916.2011.04477.x.

[11] H. Zhang, Z. Li, B.-N. Kim, K. Morita, H. Yoshida, K. Hiraga, Y. Sakka, Highly Infrared Transparent Nanometric Tetragonal Zirconia Prepared by High-Pressure Spark Plasma Sintering, J. Am. Ceram. Soc. 94 (2011) 2739-2741. doi:10.1111/j.1551-2916.2011.04680.x.

[12] J. Klimke, M. Trunec, A. Krell, Transparent Tetragonal Yttria-Stabilized Zirconia Ceramics: Influence of Scattering Caused by Birefringence, J. Am. Ceram. Soc. 94 (2011) 1850-1858. doi:10.1111/j.1551-2916.2010.04322.x.

[13] U. Anselmi-Tamburini,J.N. Woolman, Z.A. Munir, Transparent Nanometric Cubic and Te tragonal Zirconia Obtained by High-Pressure Pulsed Electric Current Sintering, Adv. Funct. Mater. 17 (2007) 3267-3273. doi:10.1002/adfm.200600959.

[14] K. Tsukuma, I. Yamashita, T. Kusunose, Transparent 8mol\% Y 203 -ZrO 2 (8Y) Ceramics, J. Am. Ceram. Soc. 91 (2008) 813-818. doi:10.1111/j.1551-2916.2007.02202.x.

[15] A.G. Evans, N. Burlingame, M. Drory, W.M. Kriven, Martensitic transformations in zirconiaparticle size effects and toughening, Acta Metall. 29 (1981) 447-456. doi:10.1016/00016160(81)90170-X.

[16] B.-N. Kim, N. Horiuchi, A. Dash, Y.-W. Kim, K. Morita, H. Yoshida, L.I. Ji-Guang, Y. Sakka, Spark plasma sintering of highly transparent hydroxyapatite ceramics, Funtai Oyobi Fummatsu 
Yakin/Journal Japan Soc. Powder Powder Metall. 64 (2017).

[17] K. Matsui, H. Yoshida, Y. Ikuhara, Review: microstructure-development mechanism during sintering in polycrystalline zirconia, Int. Mater. Rev. (2017) 1-32.

doi:10.1080/09506608.2017.1402424.

[18] B.N. Kim, K. Hiraga, K. Morita, H. Yoshida, Y.J. Park, Y. Sakka, Dynamic grain growth during lowtemperature spark plasma sintering of al umina, Scr. Mater. 80 (2014) 29-32.

doi:10.1016/j.scriptamat.2014.02.015.

[19] Y. Yoshizawa, T. Sakuma, Evolution of microstructure and grain growth in ZrO2-Y2O3 alloys., ISIJ Int. 29 (1989) 746-752. doi:10.2355/isijinternational.29.746.

[20] K. Matsui, H. Yoshida, Y. Ikuhara, Isothermal Sintering Effects on Phase Separation and Grain Growth in Yttria-Stabilized Tetragonal Zirconia Polycrystal, J. Am. Ceram. Soc. 92 (2009) 467-475. doi:10.1111/j.1551-2916.2008.02861.x.

[21] K. Matsui, H. Yoshida, Y. Ikuhara, Grain-boundary structure and microstructure development mechanism in 2-8mol\% yttria-stabilized zirconia polycrystals, Acta Mater. 56 (2008) 1315-1325. doi:10.1016/j.actamat.2007.11.026.

[22] T. Sakuma, Y. Yoshizawa, The Grain Growth of Zirconia during Anneal ing in the Cubic/Tetragonal Two-Phase Region, Mater. Sci. Forum. 94-96 (1992) 865-870.

doi:10.4028/www.scientific.net/MSF.94-96.865.

[23] G. Goldstein, D. Newbury, P. Echlin, D. Joy, C. Flori, E. Lifshin, Scanning electron microscopy and microanalysis, 1981.

[24] R. Apetz, M.P.B. Bruggen, Transparent Alumina: A Light-Scattering Model, J. Am. Ceram. Soc. 86 (2003) 480-486. doi:10.1111/j.1151-2916.2003.tb03325.x.

[25] H. C. van de Hulst, Light scattering by small particles, Q. J. R. Meteorol. Soc. 84 (1958) 198-199. doi:10.1002/qj.49708436025.

[26] H. Zhang, B.-N. Kim, K. Morita, H.Y. Keijiro Hiraga, Y. Sakka, Effect of sintering temperature on optical properties and microstructure of translucent zirconia prepared by high-pressure spark plasma sintering, Sci. Technol. Adv. Mater. 12 (2011) 055003. doi:10.1088/14686996/12/5/055003.

[27] J. Janek, C. Korte, Electrochemical blackening of yttria-stabilized zirconia - morphological instability of the moving reaction front, Solid State lonics. 116 (1999) 181-195. doi:10.1016/S0167-2738(98)00415-9.

[28] F. Zhang, K. Vanmeensel, M. Inokoshi, M. Batuk, J. Hadermann, B. Van Meerbeek, I. Naert, J. Vleugels, 3Y-TZP ceramics with improved hydrothermal degradation resistance and fracture toughness, J. Eur. Ceram. Soc. 34 (2014) 2453-2463. doi:10.1016/j.jeurceramsoc.2014.02.026.

[29] R.H.J. Hannink, P.M. Kelly, B.C. Muddle, Transformation Toughening in Zirconia-Containing Ceramics, J. Am. Ceram. Soc. 83 (2004) 461-487. doi:10.1111/j.1151-2916.2000.tb01221.x.

[30] A. V. Virkar, R.L.K. Matsumoto, Ferroelastic Domain Switching as a Toughening Mechanism in Tetragonal Zirconia, J. Am. Ceram. Soc. 69 (1986) C-224-C-226. doi:10.1111/j.11512916.1986.tb07341.x. 
[31] J.J. Roa, M. Turon-Vinas, M. Anglada, Surface grain size and texture after annealing ground zirconia, J. Eur. Ceram. Soc. 36 (2016) 1519-1525. doi:10.1016/j.jeurceramsoc.2015.12.022.

[32] M. Inokoshi, K. Vanmeensel, F. Zhang, J. De Munck, G. Eliades, S. Minakuchi, I. Naert, B. Van Meerbeek, J. Vleugels, Aging resistance of surface-treated dental zirconia, Dent. Mater. 31 (2015) 182-194. doi:10.1016/j.dental.2014.11.018.

[33] J.F. Jue, A. V. Virkar, Fabrication, Microstructural Characterization, and Mechanical Properties of Polycrystalline t'-Zirconia, J. Am. Ceram. Soc. 73 (1990) 3650-3657. doi:10.1111/j.11512916.1990.tb04271.x.

[34] R.A. Cutler, J.R. Reynolds, A. Jones, Sintering and Characterization of Polycrystall ine Monoclinic, Tetragonal, and Cubic Zirconia, J. Am. Ceram. Soc. 75 (1992) 2173-2183. doi:10.1111/j.11512916.1992.tb04480.x. 